\title{
Estratégias de permanência no ensino superior para povos indígenas em uma universidade federal
}

\section{Strategies for permanence in higher education for indigenous people in a federal university}

\section{Estrategias de permanencia en la educación superior para pueblos indígenas en una universidad federal}

\author{
Lima, Alan Lucas de Oliveira' (Redenção, Ceará e Brasil) \\ ORCID ID: https://orcid.org/0000-0003-3002-3812 \\ Kanikadan, Andrea Yumi Sugishita ${ }^{2}$ (Redenção, Ceará e Brasil) \\ ORCID ID: https://orcid.org/0000-0001-5057-4801
}

\section{Resumo}

O presente estudo tem como objetivo estudar as estratégias de permanência de estudantes indígenas no ensino superior, em uma universidade federal, localizada no interior do Ceará. O intuito é estudar práticas que vão além do ingresso de indígenas no ensino superior brasileiro, não deixando de ressaltar sua importância principalmente no que se refere a possibilidade de inserção de grupos étnicos em espaços que foram privados historicamente de ter acesso. Trata-se de pesquisa descritiva e exploratória, com abordagem qualitativa, com dados coletados a partir de entrevistas com estudantes indígenas, professores e responsáveis pela gestão de políticas públicas destinadas a permanência desses estudantes na universidade. Os dados foram analisados a partir de conceitos referentes a inclusão e permanência encontrados na literatura em questão. No que concerne aos resultados da pesquisa, observou-se que as demandas destacadas pelos entrevistados vão além de fatores econômicos e também estão relacionadas a questões culturais e sociais.

Palavras-chave: Estudantes indígenas. Ensino superior brasileiro. Estratégias de permanência.

\begin{abstract}
This paper aims to study the strategies of permanence of indigenous students in higher education, at a federal university, located in Ceará countryside. It intends to study practices that go beyond the entry of indigenous people in Brazilian higher education, emphasizing the importance of insertion of ethnic groups in spaces that have historically been deprived of access. It is a descriptive and exploratory research, with a qualitative approach, with data collected from interviews with indigenous students, teachers and those responsible for the management of public policies looking forward to the permanence of these students at the university. The data were analyzed based on concepts related to inclusion and permanence found in the literature. The results show that the demands highlighted by the interviewees go beyond economic factors and are also related to cultural and social issues.
\end{abstract}

Keywords: Indigenous students. Brazilian higher education. Permanence strategies.

\section{Resumen}

El presente estudio tiene como objetivo estudiar las estrategias de permanencia de los estudiantes indígenas en la educación superior, en una universidad federal, ubicada en el interior de Ceará. El objetivo es estudiar prácticas que van más allá de la entrada de los pueblos indígenas en la educación superior brasileña, al tiempo que enfatizan su importancia, especialmente con respecto a la posibilidad de inserción de grupos étnicos en espacios que históricamente han sido privados de acceso. Es una

${ }^{1}$ Graduação em andamento em Administração Pública. Universidade da Integração Internacional da Lusofonia Afro-Brasileira, UNILAB, Brasil. akanikadan@unilab.edu.br

2 Doutora em Ecologia Aplicada pela Universidade de São Paulo. Professora adjunta da Universidade da Integração Internacional da Lusofonia Afro-Brasileira. alan.prouca@gmail.com 
investigación descriptiva y exploratoria, con un enfoque cualitativo, con datos de entrevistas con estudiantes indígenas, maestros y los responsables de la gestión de políticas públicas dirigidas a la permanencia de estos estudiantes en la universidad. Los datos se analizaron en base a conceptos relacionados con la inclusión y la permanencia encontrados en la literatura en cuestión. Con respecto a los resultados de la investigación, se observó que las demandas destacadas por los entrevistados van más allá de los factores económicos pues están relacionadas con cuestiones culturales y sociales.

Palavras-Clave: Estudiantes indígenas. Educación superior brasileña. Estrategias de permanencia.

\section{Introdução}

O desenvolvimento social tem papel fundamental e deve ser levado em consideração, principalmente quando se busca destacar práticas que fomentem o desenvolvimento local, pois há importância na função do Estado em preservar direitos fundamentais para a sociedade e a seus respectivos grupos sociais, possibilitando a garantia de direitos individuais e coletivos.

O Estado, como ator principal na criação de políticas públicas, não possibilitou de forma efetiva a garantia e a preservação de direitos fundamentais, principalmente quando se destaca a relação do setor público com grupos étnicos que, historicamente foram subalternizados, caracterizados por uma imagem marcadamente periférica, sendo alvo de notória discriminação, como ressalta Diniz (2010).

Em relação às comunidades indígenas brasileiras, é importante destacar o processo de invisibilidade social, ou seja, entendia-se que determinados grupos que, viverem a margem da sociedade, já não mais existiam. Um processo impulsionado pela escassez de políticas públicas que incentivassem a reafirmação sociocultural e que preservassem seu território. O processo de invisibilidade ainda é bastante presente, mesmo que, no caso dos povos indígenas, segundo o censo de 2010 do IBGE, cerca de 896.917 pessoas reconheciam-se como indígenas, o que corresponde aproximadamente a $0,47 \%$ da população total do país. Ou seja, um grupo numericamente presente, porém não visibilizado.

No caso das universidades brasileiras, a presença de indígenas ainda é pouco frequente, embora tenha se intensificado nos últimos anos. Bergamaschi, Doebber e Brito (2018) destacam que, o ingresso de indígenas no ensino superior se dá pela criação de cursos específicos, como o Programa de Licenciatura Intercultural Indígena (Prolind), tendo como intuito a formação diferenciada de docentes indígenas. 
Bergamaschi, Doebber e Brito (2018) ainda ressaltam a Lei 12.711/2012, intitulada de Lei das cotas, o ingresso de indígenas por meio de licenciaturas interculturais e vagas reservadas ou suplementares.

Essas práticas, mesmo que não totalmente eficientes, pois não suprem as demandas de todos os indígenas que buscam ingressar no ensino superior, tem papel fundamental, principalmente quando se deseja destacar políticas de inserção de grupos étnicos em espaços não antes ocupados, como as universidades públicas brasileiras.

Contudo, sem deixar de ressaltar a importância de práticas de ingresso, importante também é destacar políticas de permanência, ou seja, práticas que possibilitem que, após a inserção de indígenas no ensino superior, o Estado, mesmo que de forma desconcentrada, dê condições necessárias para a permanência do indígena no ambiente acadêmico.

Desse modo, o presente trabalho tem como objetivo estudar as estratégias de permanência de indígenas no ensino superior, realizando um estudo na em uma universidade federal, com sede no estado do Ceará.

Observou-se ainda, a pouca produção científica que tenha como objetivo o estudo de indígenas no ensino superior brasileiro, destacando-se a lacuna de estudos sobre políticas de inserção, práticas, institucionais ou não, que garantam a permanência desses indivíduos. A escolha da universidade se deu pela aproximação do autor com a instituição e por ser uma universidade que, mesmo tendo aderido recentemente a políticas de ingresso para estudantes indígenas, já conta com estudantes de diversas comunidades indígenas, que possuem especificidades distintas e que estão espalhadas por todo estado.

\section{Metodologia}

Inicialmente, realizou-se a leitura de trabalhos acadêmicos sobre a inserção e permanência de indígenas no ensino superior brasileiro. Utilizaram-se como palavras-chave para a pesquisa os termos: "Ações afirmativas para indígenas", "Inserção de indígenas no ensino superior", "Indígenas na universidade" e "Permanência de indígenas no ensino superior brasileiro", buscando selecionar trabalhos acadêmicos que abordassem em seu estudo experiências de universidades 
brasileiras na implementação e execução dessas políticas, trabalhos acadêmicos que destacassem a importância de políticas de ingresso e permanência nas universidades brasileiras e selecionar também, trabalhos que ressaltassem os principais gargalos que contribuem para a não permanência desses indivíduos no ambiente acadêmico.

Desse modo, o presente estudo tem como objetivo a realização de uma pesquisa descritiva e exploratória, pois além de utilizar-se de materiais acadêmicos já existentes sobre a permanência de estudantes indígenas no ensino superior para desenvolver o referencial teórico, também realizou-se uma sondagem sobre o fato estudado numa universidade federal. Para Gil $(2008$, p. 28$)$ a pesquisa descritiva e exploratória tem "como objetivo primordial a descrição das características de determinada população ou fenômeno ou o estabelecimento de relações entre variáveis".

Em relação a abordagem da pesquisa, utilizou-se uma abordagem qualitativa, observando que, analisou-se os dados coletados através de entrevistas com estudantes indígenas, professores e responsáveis pela gestão de políticas públicas destinadas a permanência desses estudantes, fazendo assim uma análise valorativa. "A pesquisa qualitativa não se preocupa com representatividade numérica, mas, sim, com o aprofundamento da compreensão de um grupo social, de uma organização, etc." (GERHARDT; SILVEIRA, 2009, p. 31).

No que concerne as entrevistas, com o intuito de torná-las mais abrangentes, utilizou-se o modelo de entrevista não estruturado. Observa-se que, apesar do entrevistador não elaborar questões específicas para os entrevistados, pode, no decorrer da entrevista aprofundar-se nos pontos pré-selecionados, da forma como achar mais conveniente e oportuno para a pesquisa realizada. Júnior e Júnior (2011, p.240) destacam que, "o tipo de entrevista informal é o menos estruturado possível e só se distingue da simples conversação porque tem como objetivo básico a coleta de dados".

Desse modo, com o objetivo de auxiliar os assuntos que foram abordados no decorrer das entrevistas, utilizaram-se os seguintes pontos principais:

- A relação do indígena com a universidade;

- As principais dificuldades enfrentadas;

- A permanência do indígena no ensino superior. 
As entrevistas tiveram os estudantes indígenas como grupo principal, contudo, também foram realizadas entrevistas com professores e representantes institucionais.

Em relação aos estudantes indígenas entrevistados, optou-se por selecionar pelo menos dois estudantes de cada comunidade indígena, observando que as comunidades indígenas possuem características comuns e distintas. Também foram entrevistados estudantes representantes do movimento indígena dentro da universidade.

Todas as entrevistas foram realizadas presencialmente e aconteceram na própria Instituição no período de quatro meses, de fevereiro a maio de 2019. Deve-se ainda ressaltar que, utilizou-se de algumas plataformas digitais para agendar as entrevistas.

Em relação as dificuldades relacionadas a coleta de dados, destaca-se a obtenção de informações sobre a quantidade de estudantes ativos na Instituição, de quais comunidades indígenas vieram e como estão distribuídos pelos cursos da Universidade. Como o ingresso de estudantes indígenas na Universidade é bastante recente, a Instituição está organizando os dados quantitativos referentes a esses estudantes. Assim, a Diretoria acadêmica disponibilizou Relatório de Estudantes Autodeclarados Indígenas (2019) com dados que facilitaram este estudo.

Os procedimentos utilizados nessa pesquisa foram o bibliográfico e 0 documental. São procedimentos que seguem os mesmos caminhos, apenas as fontes de consulta se diferenciam: bibliográfica, "livros e artigos científicos localizados em bibliotecas" e documental: "tabelas estatísticas, jornais, revistas, relatórios, documentos oficiais, cartas, filmes, fotografias, pinturas, tapeçarias, relatórios de empresas, vídeos de programas de televisão, etc. (FONSECA, 2002, p. 32).

Assim, realizou-se a seleção de trabalhos acadêmicos para construir o referencial teórico, além de programas e leis que serviram para fundamentar o estudo realizado. A pesquisa foi realizada em uma Universidade Pública Federal com sede no interior do estado do Ceará.

\section{Políticas públicas educacionais para povos indígenas}


Segundo Secchi (2013), pode-se definir política pública como uma diretriz criada para combater um problema público entendido como coletivamente relevante. Souza (2007), de maneira resumida, caracteriza políticas públicas como "o campo do conhecimento que busca, ao mesmo tempo, 'colocar o governo em ação' e/ou analisar essa ação e, quando necessário, propor mudanças no rumo ou curso dessas ações". Desse modo, a Administração Pública, com o objetivo de solucionar problemas, através da criação de políticas públicas, assume função fundamental na redução de desigualdades sociais.

Em relação ao processo educativo, a produção de conhecimento, desde o ensino básico até o ensino superior, influência de forma direta na qualidade de vida da sociedade. Apesar do Brasil, nos últimos anos ter aumentado o investimento na área da educação, ainda se encontra em crescimento tardio comparado com países desenvolvidos ou com alguns países em desenvolvimento. $O$ conhecimento, a capacidade de processar e selecionar informações, a iniciativa e a criatividade, constituem matérias-primas fundamentais para as grandes economias (MELLO, 1991).

Com o intuito de diminuir desigualdades, as políticas compensatórias possibilitam através de mecanismos como as ações afirmativas, por exemplo, que determinados grupos sociais possam ter acesso a espaços públicos e privados, garantindo a igualdade de oportunidades e tratamento. Desse modo, essas políticas, como as cotas, permitem que o Estado inclua povos excluídos no curso da história, possibilitando a inserção de grupos étnicos em espaços que até então foram privados de acesso. Em relação a demanda de vagas destinadas para povos indígenas, Lima (2007) nos relata que, os indígenas têm procurado o ensino superior para incorporar saberes novos e, a partir disso, participar de um espaço que formule estratégias contra hegemônicas.

Em relação as comunidades indígenas brasileiras, é importante destacar que muitas das políticas públicas destinadas a esses grupos só foram incluídas nas agendas governamentais como consequência da luta do movimento indígena, que busca a garantia de direitos fundamentais, relacionados principalmente a questões socioambientais e humanitárias. 
Como já falado, as ações afirmativas para o ingresso de indígenas no ensino superior são de notória importância, observando que, sem os mecanismos já criados, essas pessoas teriam que passar pelo processo tradicional já adotado nas universidades públicas. Ou seja, teriam que concorrer através do Sistema de Seleção Unificada (Sisu) ou por meio dos vestibulares próprios das universidades. Desse modo, sem as políticas compensatórias, as universidades não conseguiriam de forma efetiva, ter em seu quadro de alunos um número considerável de estudantes indígenas, já que seu acesso à educação esteve sempre negligenciado. Estácio (2015) destaca que as ações afirmativas podem ser entendidas como um grupo de ações e orientações que protegem as minorias e os grupos que tenham sido discriminados no passado, não combatendo apenas os flagrantes de discriminação, mas também a discriminação que está enraizada na sociedade. Estácio $(2015$, p.10) ressalta ainda que:

\begin{abstract}
Tais ações não deverão ter características exclusivamente assistencialistas, mas pensadas como política efetiva do Estado com o fito de garantir e fortalecer a trajetória acadêmica dos alunos e alunas afrodescendentes, pessoas com deficiência, indígenas e quilombolas. Isso reforça a concepção de que a implementação do sistema de quotas nas universidades brasileiras deverá ser pensada, conjuntamente, com programas e projetos de permanência no ensino superior. Isso porque não é suficiente apenas garantir uma vaga na universidade aos afrodescendentes, indígenas, pessoas com deficiência, quilombolas, entre outros, mas também é preciso garantir-lhes condições adequadas de continuidade dos estudos e de formação acadêmica e científica, proporcionando-lhes uma permanência material e simbólica exitosa (ESTÁCIO, 2015, p.10).
\end{abstract}

Apesar das críticas feitas em relação à criação das políticas compensatórias por parte da sociedade, principalmente quando se acredita que as mesmas ferem a igualdade formal, que expressa a igualdade de todos os indivíduos perante a lei, é importante destacar que, as medidas adotadas pelo Estado com o objetivo de compensar grupos étnicos ou não, historicamente prejudicados e ainda discriminados, tem como justificativa a igualdade material, onde o tratamento deve ser desigual a pessoas que se encontram em condições desiguais, na proporção de suas desigualdades.

Sobre o dever do Estado em garantir direitos fundamentais, a Constituição Federal de 1988, no artigo 205, garante que todos tenham acesso à educação, sem 
restrições que limitem o ingresso de grupos étnicos em virtude de suas diferenças. Ferri e Bagnato (2018, p.25) destacam a necessidade de criação de estratégias que garantam tais princípios constitucionais ressaltando que isso está relacionado à garantia de direitos humanos, ou seja, a garantia de acesso às políticas que suprem as necessidades essenciais.

Apesar das ações afirmativas serem consideradas um avanço relacionado a diminuição de gargalos que impedem a introdução de indígenas nas universidades públicas brasileiras, diminuindo restrições e as desigualdades de concorrências, Santos (2009) expressa que essas políticas devem ir além de seu objetivo principal, que seria a inserção. Desse modo, pensar em políticas que garantam a permanência desses grupos étnicos no ensino superior é fundamental para a efetivação dessas políticas públicas. Estácio (2015) também ressalta que, as ações afirmativas não devem se restringir a reserva de vagas para minorias étnicas ou raciais, pois tais políticas devem ir além das cotas e tornar evidente que é possível, no caso da sociedade brasileira, redistribuir políticas compensatórias.

Assim, torna-se necessário entender o conceito e as condições básicas que garantam a permanência de indígenas na universidade. Para Estácio (2015) a permanência possui uma concepção de tempo que é cronológica e outra simbólica, permitindo a existência de diálogo, a troca de experiência e a transformação de todos e de cada um. Assim, deve-se entender que, o conceito de permanecer está além do sentido de durar no tempo, ou seja, o indivíduo deve criar uma integração com o espaço e com os indivíduos que nele estão inseridos.

A permanência de indígenas no ensino superior está relacionada a diversos fatores que interferem direta ou indiretamente em sua relação com o espaço acadêmico. Santos (2009) divide esses fatores em dois tipos, um voltado para questões materiais, ou seja, para se manter na universidade o aluno precisa de dinheiro para se alimentar, para se locomover, dinheiro com material e etc. O segundo fator engloba questões relacionadas ao apoio pedagógico, a valorização da autoestima e etc. Neste caso, Santos (2009) o denomina como permanência simbólica.

As vulnerabilidades socioeconômicas vivenciadas pelas comunidades indígenas não proporcionam aos estudantes condições básicas para se manterem na 
universidade. Os gastos são diversos e a carga horária do ensino e a escassez de emprego, não possibilitam, na maioria das vezes, que os estudantes exerçam alguma atividade econômica. Quanto encontram uma oportunidade de trabalho, abrem mão da vivência plena na universidade, o que impacta em sua permanência simbólica (SANTOS, 2009, p.73). Assim, para continuar seus estudos, os estudantes dependem de políticas de assistência estudantil, que os auxiliam com gastos relacionados a permanência.

Como exemplo de política de assistência estudantil, o Plano Nacional de Assistência Estudantil (Pnaes), instituído pelo Decreto n ${ }^{0} 7.234$, de 19 de julho de 2010, apoia a permanência de estudantes de baixa renda matriculados em cursos de graduação presencial das instituições federais de ensino superior (Ifes). O plano tem como objetivo principal a igualdade de oportunidades, possibilitando a melhoria do desempenho acadêmico e reduzindo situações de repetência e evasão. Bergamaschi, Doebber e Brito (2018) relatam que, mesmo o Pnaes não fazendo em seu texto referência direta à assistência de estudantes indígenas, o plano tem notória importância no que tange a elaboração de estratégias para manter esses estudantes nas instituições.

De maneira específica, os estudantes indígenas, quilombolas e em situação de vulnerabilidade socioeconômica podem pleitear a participação no Programa Bolsa Permanência. Segundo o Ministério da Educação, o Programa é uma política pública voltada a concessão de auxílio financeiro, podendo assim, contribuir para a permanência e a diplomação dos beneficiados. Os estudantes ainda podem participar de bolsas relacionadas a pesquisa, ensino, extensão e estágios remunerados.

Além da dificuldade financeira, outros gargalos contribuem para a não permanência do indígena no ensino superior. Como exemplo, o sentimento de não pertencimento. Na universidade, os estudantes estão afastados de suas comunidades e o convívio universitário, e sem um acompanhamento inicial, podem ficar isolados, não permitindo a sua efetiva adaptação.

A presença de indígenas no ensino superior ainda é recente e tem se intensificado com a intervenção do Estado em criar políticas públicas de inserção. Contudo, esses espaços ainda são marcadamente elitizados. Santos (2012) expressa 
que o ensino superior brasileiro, ao longo da história, sempre se pautou por uma tendência mais elitista, resultado da exclusão de grupos sociais menos favorecidos.

Santos (2009) evidencia que a sociedade estabelece formas para classificar os indivíduos e o total de atributos considerados comuns e naturais aos membros de cada categoria social.

Desse modo, a exclusão, a discriminação e o isolamento acontecem pela falta de integração do indígena com o ambiente e com os indivíduos que o compõem, impedindo a permanência simbólica pela inadaptação e/ou discriminação (ESTÁCIO, 2015, p.10).

Santos (2009) nesse contexto, revela-nos que, para reverter essa situação que colabora para o não pertencimento, é necessário que as desigualdades de equilíbrio sejam diminuídas.

Deve-se evidenciar práticas que buscam reduzir desigualdades, como exemplo destaca a interiorização do ensino superior que busca a democratização do acesso à educação, permitindo a criação de espaços acadêmicos mais plurais e diversos.

Em relação as instituições, as universidades assumem atribuições fundamentais na inclusão de indígenas em seu corpo discente, ou seja, deve-se reconhecer os grandes desafios que essas instituições assumem, com o objetivo de criar um espaço acadêmico mais plural e democrático.

[...] a permanência dos estudantes indígenas nas universidades é um grande desafio para essas instituições e que o diálogo e a postura aberta e receptiva à contribuição dos saberes e conhecimentos desses povos são ainda pouco observados. A sensibilização institucional das universidades para realizar a escuta efetiva e afetiva dos saberes e conhecimentos indígenas poderá ser o primeiro passo para processos de interculturalidade no âmbito acadêmico". (BERGAMASCHI; DOEBBER; BRITO, 2018, p.34)

Paladino (2013) expressa que a universidade deve acompanhar de forma qualificada os estudantes indígenas, principalmente quando se refere a questões pedagógicas, culturais e políticas, permitindo através dessas ferramentas a permanência dos mesmos. 


\section{Resultados e discussões}

Segundo dados fornecidos pela Diretoria acadêmica da Universidade, oitenta e oito estudantes indígenas estão matriculados na Instituição em cursos de graduação. Esses estudantes estão distribuídos pelos cursos de Administração Pública, Agronomia, Antropologia, Ciências Biológicas, Enfermagem, Engenharia de Energias, História, Humanidades, Letras - Língua Portuguesa, Pedagogia, Química, Relações Internacionais e Sociologia.

Tabela 1 - Distribuição dos estudantes indígenas pelos cursos de graduação

\begin{tabular}{lrr}
\hline \multicolumn{1}{c}{ Curso } & \multicolumn{2}{c}{$\begin{array}{c}\text { Número de } \\
\text { matriculados }\end{array}$} \\
\hline Humanidades & 16 & 18,2 \\
Agronomia & 15 & 17,0 \\
Pedagogia & 13 & 14,8 \\
Administraçāo Pública & 10 & 11,4 \\
História & 7 & 8,0 \\
Letras & 6 & 6,8 \\
Ciências Biológicas & 5 & 5,7 \\
Antropologia & 4 & 4,5 \\
Enfermagem & 4 & 4,5 \\
Quimica & 3 & 3,4 \\
Sociologia & 3 & 3,4 \\
Engenharia de Energias & 1 & 1,1 \\
Relaçōes Internacionais & 1 & 1,1 \\
Total & $\mathbf{8 8}$ & $\mathbf{1 0 0}$ \\
\hline
\end{tabular}

Fonte: Elaborado pelo au autor (2019)

Deve-se destacar que esses estudantes ingressaram na Universidade através dos programas tradicionais de ingresso, como o Sistema de Seleção Unificada (Sisu) e o Sistema de Seleção Utilizando os Resultados do Enem (SiSURE) ou por meio de programas de seleção internos, como os editais específicos ofertados por alguns cursos.

É importante evidenciar que as vagas disponibilizadas para indígenas através dos editais específicos ofertados pelos cursos são vagas ociosas, ou seja, vagas que não foram preenchidas através dos programas de seleção tradicionais. Desse modo, caso fossem preenchidas todas as vagas ofertadas pelo Sisu ou SiSURE não sobrariam vagas para a inserção de indígenas através dos editais específicos. Com isso, nota-se a necessidade de se existir políticas mais específicas que levem em conta as discussões propostas por Estácio (2015), as quais possam 
proteger minorias e grupos discriminados no passado, além de incluir pautas do movimento indígena para seu aprimoramento conforme destaca Lima (2007).

Tabela 2 - Status dos estudantes indígenas entre os semestres 2011.2 e 2019.1

\begin{tabular}{lrr}
\hline \multicolumn{1}{c}{ Situaçāo } & \multicolumn{2}{c}{$\begin{array}{c}\text { Número de } \\
\text { estudantes }\end{array}$} \\
\hline Ativo & 88 & 77,2 \\
Cancelado & 13 & 11,4 \\
Trancado & 1 & 0,9 \\
Concluído & 12 & 10,5 \\
\hline Total & $\mathbf{1 1 4}$ & $\mathbf{1 0 0}$ \\
\hline
\end{tabular}

Fonte: Elaborado pelo autor (2019)

No que tange a evasão de estudantes indígenas da Instituição de ensino, os dados disponibilizados pela Diretoria acadêmica da Universidade apontam que, entre os semestres 2011.2 e 2019.1 (Tabela 2). Trata-se de número relevante, dado o total de estudantes indígenas que ingressou na universidade. Caso não tivessem desistido dos cursos, possivelmente haveria um número maior de graduados e dessa forma, mais profissionais indígenas atuando na sociedade.

Essas informações são importantes pois reforçam a necessidade de existir na universidade setores que realizem o acompanhamento desses estudantes para que se conheça a razão pela qual desistem dos cursos. Além disso, as demandas apresentadas a seguir influenciam não somente na permanência do indígena no ensino superior, mas no tempo em que esses indivíduos levam para concluir suas graduações. Ou seja, mesmo que o estudante permaneça na universidade, ele tende, na maioria das vezes, a prorrogar seu tempo na instituição.

Em relação aos depoimentos relacionados a permanência desses estudantes na Universidade, observou-se que, apesar dos estudantes virem de comunidades distintas, a maioria das demandas possuem características comuns e assemelham-se. Ou seja, os estudantes indígenas entrevistados enfrentam, na maioria das vezes, as mesmas dificuldades após ingressarem no ensino superior.

Ao ingressar na Universidade, todos os estudantes entrevistados alegam necessitar de alguma ajuda financeira da Instituição para dar continuidade aos seus 
estudos. Quando contemplados com algum benefício, os estudantes utilizam o recurso para gastos com moradia, alimentação, transporte. Santos (2009), ao caracterizar os fatores materiais destaca que, para se manter na universidade o aluno precisa de dinheiro para se alimentar, para se locomover, dinheiro com material e etc.

Em relação aos benefícios financeiros, os estudantes indígenas em situação de vulnerabilidade socioeconômica podem se candidatar aos auxílios financeiros ofertados pelo própria Universidade através do Programa de Assistência ao Estudante. Os estudantes indígenas se encaixam no perfil dos usuários aptos a participarem do Programa Bolsa Permanência. Contudo, todos os estudantes entrevistados ressaltaram a dificuldade para acessar tal política. Eles destacaram que a demasiada burocracia para ingressar no programa torna o processo lento e desestimulante. Alguns estudantes relatam que, tiveram que esperar mais de seis meses após ingressarem na Instituição para receber algum tipo de bolsa ou auxílio financeiro.

As entrevistas mostram que a demora para ter acesso a programas como esse é um dos motivos determinantes na permanência desses indivíduos, principalmente quando são observadas as dificuldades dos recém chegados na Instituição. Os estudantes destacam que os primeiros meses podem ser definidos como os mais difíceis, pois a maioria desses indivíduos não possui renda alguma, aqui deve-se salientar a alta fragilidade financeira dessas famílias indígenas. Ou seja, sem a ajuda de políticas financeiras esses estudantes ficam impossibilitados de suprir suas necessidades mais básicas. Os estudantes ainda relatam a alta dificuldade de conseguir emprego devido à dificuldade de conciliar com o tempo destinado aos estudos e a escassez de oferta de vagas no mercado de trabalho. Conforme Santos (2009) destacou que, na tentativa de permanecer materialmente, os estudantes podem deixar de vivenciar a universidade em sua plenitude para que possam trabalhar e essa escolha tem impactos que repercutem de forma distinta sobre o desempenho e sobre a vida acadêmica.

Desse modo, os estudantes indígenas recém ingressos ficam nos primeiros meses descobertos de qualquer política de assistência financeira e são forçados a adotar práticas alternativas para conseguir satisfazer suas necessidades mais básicas. Como exemplo, os estudantes descreveram que enquanto não eram 
assistidos por nenhuma política financeira precisaram da ajuda de colegas e professores para cobrir gastos com moradia e alimentação.

Uma medida que poderia ser utilizada para acelerar o processo de inclusão de indígenas em programas financeiros seria a possibilidade de se fazer o cadastro desses estudantes antes destes começarem suas atividades na instituição. Assim, quando o estudante indígena fosse realizar sua matrícula no curso de graduação, já seria solicitado pela Instituição todos os documentos necessários para a adesão aos programas financeiros. Atualmente os estudantes só podem solicitar algum tipo de benefício após o início do período letivo e precisam esperar os respectivos editais de inscrição. Os entrevistados destacam que a abertura desses editais não coincide com o período de ingresso, principalmente os editais referentes ao Programa Bolsa Permanência.

A distância entre a comunidade indígena e a Universidade também foi expressa como um dos fatores que influencia na permanência, pois, além de ingressarem em um ambiente diferente do seu convívio e com uma cultura distinta da sua, esses indivíduos são separados de suas famílias e passam a vivenciar uma nova rotina. Santos (2009) ressalta os aspectos simbólicos que envolvem a permanência, sendo necessário que esse ambiente universitário seja convidativo ao estudante indígena.

Devido à grande distância entre as comunidades indígenas e a Universidade, muitos dos estudantes não conseguem voltar para as suas residências todos os dias e necessitam residir nos municípios onde a Universidades está situada ou em municípios vizinhos. A escolha por municípios vizinhos acontece pelo alto custo dos alugueis nas cidades onde a Universidade está localizada, principalmente no município sede da Universidade. Cabe destacar que, mesmo a Universidade pertencendo a um projeto de interiorização, os dados obtidos com esse estudo mostram que ainda é necessário a existência de outras políticas para contemplar o que Santos (2009) coloca sobre práticas para reduzir desigualdades.

Muitos estudantes indígenas, assim como os demais estudantes que residem no município sede ou em cidades vizinhas, optam por, quando possível, na maioria das vezes em feriados ou em finais de semana, voltar para as suas comunidades de origem. Os alunos que conseguem ir para Universidade e voltar no 
mesmo dia para suas residências alegam o excesso de cansaço, falta de segurança nos transportes públicos e alto gasto com locomoção. Dos entrevistados, há apenas um pequeno grupo de estudantes que consegue voltar para as suas comunidades todos os dias, pois se trata de uma comunidade próxima à Universidade.

Em relação ao desempenho educacional dentro da Instituição, os estudantes relatam a dificuldade de acompanhar as atividades acadêmicas devido à pouca familiaridade com os assuntos abordados nas disciplinas dos cursos. Destacam ainda que, além dos professores não adotarem um modelo de ensino diferenciado, levando em consideração as condições distintas dos alunos, poucas disciplinas possuem alunos monitores que devem auxiliar o desenvolvimento das atividades, favorecendo a integração de conhecimentos. Logo, os estudantes indígenas precisam estudar sozinhos e muitas vezes não conseguem compreender os conteúdos ministrados em sala de aula.

A falta de um acompanhamento pedagógico também pode contribuir para a não permanência desses estudantes, considerando-se as dificuldades em acompanhar o modelo educacional adotado pelas universidades, que na maioria das vezes, difere do modelo de ensino vivenciado em sua educação básica. Desse modo, a dificuldade em acompanhar o ensino ministrado nas universidades pode desestimular o estudante indígena. No mesmo sentido, Paladino (2013) expressa a necessidade de a universidade em acompanhar de maneira qualificada esses estudantes, principalmente quando se trata de questões pedagógicas, culturais e políticas, possibilitando que, através dessas ferramentas, esses indivíduos permaneçam no ensino superior.

Ainda em relação ao acompanhamento pedagógico, seria importante um envolvimento de docentes numa discussão sobre adoção de novas práticas de ensino voltadas para a aprendizagem de grupos étnicos, o que resultaria na criação de métodos e técnicas pedagógicos que tornassem mais eficientes a aprendizagem para estudantes indígenas.

Assim, é perceptível que programas de acompanhamento pedagógico específico para indígenas no ensino superior sejam fundamentais no desempenho acadêmico desses indivíduos e devem ser implementados com a finalidade de diminuir desigualdades de aprendizagem. Segundo os entrevistados, faz-se 
necessário um acompanhamento pedagógico que ultrapasse o espaço da sala de aula e que trabalhe especificamente em cima de suas dificuldades e limitações.

Outro fator apontado pelos entrevistados que pode determinar a permanência é o sentimento de não pertencimento ao ambiente acadêmico. Os estudantes relatam que, apesar da existência de grupos dentro da Universidade que buscam inseri-los e fazer com que se sintam parte da Instituição, ressaltam que, principalmente nos primeiros meses após o seu ingresso na Universidade, sentem-se não se encaixar no ambiente em que os rodeia, prevalecendo a ausência do sentimento de acolhimento.

Esse sentimento de não pertencimento pode ser explicado por Santos (2012) quando expressa que, ao longo da história brasileira, o ensino superior se pautou por uma tendência mais elitista, resultado da exclusão de grupos sociais menos favorecidos, como os povos indígenas. Como solução, Estácio (2015) sugere que é necessário que as desigualdades de equilíbrio de poder sejam diminuídas ou, preferencialmente, eliminadas.

\section{Considerações finais}

O presente estudo buscou, através dos relatos dos estudantes, entender quais são os principais fatores relacionados a permanência de indígenas nas universidades brasileiras, fazendo uma análise através das experiências dos estudantes indígenas em uma Universidade Federal Pública, no interior do Ceará.

As políticas compensatórias assumem função fundamental, pois permitem a inserção de grupos étnicos em espaços que foram historicamente privados de acessar. No caso do ensino superior brasileiro, observa-se que, sem as políticas de ingresso, que buscam diminuir desigualdades educacionais, as comunidades indígenas não conseguiriam ingressar efetivamente nas instituições de ensino. Neste estudo, é perceptível que, sem a criação dos editais específicos para indígenas, muitos dos estudantes não estariam na Universidade.

Apesar da notoriedade das políticas de ingresso, observando que são consideradas um avanço relacionado a diminuição de gargalos que impedem a inserção de indígenas no ensino superior, conclui-se que essas políticas não são suficientes para garantir a efetiva permanência do indígena. Desse modo, não basta 
criar mecanismos que permitam o ingresso desses indivíduos nas universidades, é importante garantir, por meio da criação de mais políticas públicas, que o indígena após ingressar, permaneça e consiga concluir com êxito sua graduação.

Com o recente acesso de indígenas na Universidade, a Universidade estudada assume uma função fundamental, observando a responsabilidade da Instituição em promover uma formação de qualidade firmada no ensino, pesquisa e extensão. Dos desafios enfrentados pela Instituição de ensino, que são diversos, destaca-se que, a busca para inserir grupos étnicos em seu corpo discente, com demandas e características distintas, ou seja, pensar em políticas de permanência que contemplem todas as especificidades e características singulares, demanda grandes esforços.

No que se refere aos fatores que podem determinar a permanência, destacam-se fatores financeiros, culturais, territoriais e sociais. De modo geral, observou-se que sem o auxílio das políticas públicas voltadas para a permanência, a maioria dos estudantes não conseguiria permanecer na universidade.

\section{Referências}

BRASIL. Ministério da Educação (MEC). Portaria $\mathbf{n}^{\circ} \mathbf{3 8 9}$, de 9 de maio de 2013. Cria o Programa de Bolsa Permanência e dá outras providências. Diário Oficial da União, Brasília, 13 maio 2013. Seção 1, p. 12.

BRASIL. Constituição da República Federativa do Brasil, 1988.

BERGAMASCHI, Maria Aparecida; DOEBBER, Michele Barcelos; BRITO, Patrícia Oliveira. Estudantes indígenas em universidades brasileiras: um estudo das políticas de acesso e permanência. Revista Brasileira de Estudos Pedagógicos, Brasília, v. 99, n. 251, p.37-53, jan. 2018.

DINIZ, Regina Lúcia Portela. Crescimento e Desenvolvimento da Criança Indígena: Um Estudo da Etnia Pitaguary - Ceará. 2010. 179 f. Tese (Doutorado) Curso de Pós-graduação em Saúde Pública, Universidade de São Paulo, São Paulo, 2010.

ESTÁCIO, Marcos André Ferreira. A presença indígena no ensino superior: a experiência da universidade do Estado do Amazonas. 2015. Disponível em: <http://www.snh2015.anpuh.org/resources/anais/39/1434417394_ARQUIVO_Aprese ncaindigenanoES-ArtigoCompleto.pdf>. Acesso em: 11 abri. $201 \overline{9}$.

FERRI, Erika Kaneta; BAGNATO, Maria Helena Salgado. Políticas públicas de Ação Afirmativa para indígenas na Universidade Estadual de Mato Grosso do Sul: a visão 
dos implementadores. Pro-posições, [s.I.], v. 29, n. 1, p.54-82, abr. 2018. FapUNIFESP (SciELO). http://dx.doi.org/10.1590/1980-6248-2016-0133.

FONSECA, J. J. S. Metodologia da pesquisa científica. Fortaleza: UEC, 2002. Apostila.

GERHARDT, Tatiana Engel; SILVEIRA, Denise Tolfo. Métodos de Pesquisa. [S. I.]: Editora da Universidade Federal do Rio Grande do Sul, 2009

GIL, Antonio Carlos. Métodos e técnicas de pesquisa social. 6. ed. São Paulo: Editora Atlas, 2008. p. 26-154.

IBGE, Instituto Brasileiro de Geografia e Estatística. Censo demográfico, 2010. IBGE, 2010.

JÚNIOR, Álvaro Francisco de Britto; JÚNIOR, Nazir Feres. A utilização da técnica da entrevista em trabalhos científicos. Evidência, Araxá, v. 7, n. 7, p. 237-250, 2011.

LIMA, A. C. de S. Ensino superior para indígenas: sobre cotas e algo mais. Seminário Formação Jurídica e Povos Indígenas: desafios para a educação superior. Belém: Laced, 2007.

MELLO, Guiomar Namo de. Políticas públicas de educação. Estudos Avançados, São Paulo, v. 5, n. 13, p.7-47, set./dez. 1991.

PALADINO, M. Um mapeamento das ações afirmativas voltadas aos povos indígenas no ensino superior. In: BERGAMASCHI, M. A.; NABARRO, E.; BENITES, A. (Orgs). Estudantes indígenas no ensino superior: uma abordagem a partir da experiência na UFRGS. Porto Alegre: Ed. da UFRGS, 2013.

PRESIDÊNCIA DA REPÚBLICA CASA CIVIL. Decreto $n^{\circ}$ 7234, de 19 de julho de 2010. Dispõe sobre o Programa Nacional de Assistência Estudantil - PNAES. Brasília, 20 jul. 2010.

SANTOS, Dyane Brito Reis. Para Além Das Cotas: A Permanência De Estudantes Negros No Ensino Superior Como Política De Ação Afirmativa. 2009. 215 f. Tese (Doutorado) - Curso de Doutorado em Educação, Universidade Federal da Bahia, Salvador, 2009.

SANTOS, Manoel Gonçalves dos. UNIVERSIDADE CONTEMPORÂNEA: ELITIZAÇÃO E INFLUÊNCIA DO IDEÁRIO NEOLIBERAL. 2012. Disponível em: <http://educonse.com.br/2012/eixo 13/PDF/42.pdf>. Acesso em: 11 abri. 2019.

SECCHI, Leonardo. Políticas Públicas: Conceitos, Esquemas de análise, Casos práticos. 2. ed. São Paulo: Cengage Learning, 2013. 188 p. 
SOUZA, Celina. Estado da Arte da Pesquisa em Políticas Públicas. In: HOCHMAN, G., ARRETCHE, M., MARQUES, E., orgs. Políticas públicas no Brasil. Rio de Janeiro: Editora FIOCRUZ, 2007.

\title{
UNIVERSIDADE FEDERAL. Diretoria Acadêmica. Relatório de Estudantes
} Autodeclarados Indígenas 2019. Ceará, 2019.

\author{
Alan Lucas de Oliveira Lima \\ Redenção, CE, Brasil \\ Graduação em andamento em Administração Pública. \\ Universidade da Integração Internacional da Lusofonia Afro-Brasileira, UNILAB, Brasil.
}

Link do Lattes: http://lattes.cnpq.br/6272175592735665

\section{Andrea Yumi Sugishita Kanikadan}

Redenção, CE, Brasil

Possui graduação (2000) e mestrado (2005) em Administração pela Universidade de São Paulo e doutorado em Ecologia Aplicada pela Universidade de São Paulo (2014). Realizou estágio doutoral pelo programa BEPE- FAPESP na Universidade de Toulouse Le-Mirail (2012-2013). Atualmente é professora adjunta da Universidade da Integração Internacional da Lusofonia Afro-Brasileira. Tem experiência na área de Administração, atuando principalmente nos seguintes temas: comunidades quilombolas, indígenas, agricultura familiar, desenvolvimento local, qualidade de vida no trabalho e políticas públicas

Link do Lattes: http://lattes.cnpq.br/8061259946864185

Recebimento: 29/05/2020

Aprovação: 05/06/2020

\section{Q.Code}

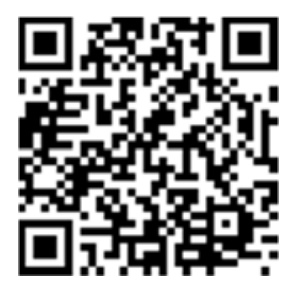

\section{Editores-Responsáveis}

Dr. Enéas de Araújo Arrais Neto, Universidade Federal do Ceará, UFC, Ceará, Brasil

Dr. Sebastien Pesce, Universidade de Orléans, França 